\title{
PROSTHETIC MAINTENANCE AND PERI- IMPLANT TISSUES CONDITIONS OF FIXED SCREW- RETAINED IMPLANT PROSTHESIS VERSUS IMPLANT-RETAINED BALL OVERDENTURES: A RANDOMIZED CLINICAL TRIAL
}

\author{
Nourhan Ahmed Ragheb", Hisham Mahmoud Abada** and Dalia Rasheed Issa ${ }^{* * *}$
}

\begin{abstract}
The aim of the study is to compare the prosthetic maintenance requirements between implantretained ball overdentures versus fixed screw-retained implant prosthesis. Clinical and radiographic changes in peri-implant tissue with using PGE $_{2}$ as a peri-implant crevicular fluid (PICF) biomarker were also evaluated. 54 completely edentulous patients were enrolled: group I, 27 patients were rehabilitated with fixed screw retained restorations; group II, 27 patients with ball retained implant overdenture. Prosthodontic complications were calculated. The clinical parameters were recorded and PICF was collected at baseline, 6- and 12-months postoperatively. There was no statistically significance difference between group I and group II regarding the frequency of maintenance of prosthetic parts of both types of restorations. There was a statistically significance difference between group I and group II regarding the frequency of maintenance of implant components. At 6- and 12-month observation periods, group I showed statistically significant lower mean plaque index, gingival index, and pocket depth compared with group II $(\mathrm{P}<.001)$. There was a statistically significant higher peri-implant marginal bone loss for group II compared with group I. There was no statistically significant difference in $\mathrm{PGE}_{2}$-PICF levels between the two groups $(P>.05)$. There was no difference in the frequency of maintenance of prosthetic parts between fixed screw retained restorations and ball retained over denture while the fixed screw retained restorations showed lower rate of maintenance of implant components. The screw retained group was more vulnerable than the ball group with respect to maintaining peri-implant tissue health.
\end{abstract}

KEY WORDS: Prosthetic maintenance, dental implant, peri-implant tissue, $\mathrm{PGE}_{2}$.

\footnotetext{
* Lecturer, Department of Prosthodontics, Faculty of Oral \& Dental Medicine, Kafrelsheikh University, Kafr El-Sheikh, Egypt. ** Lecturer, Department of Endodontics, Faculty of Oral \& Dental Medicine, Kafrelsheikh University, Kafr El-Sheikh, Egypt. *** Lecturer, Department of Periodontology and Oral Medicine, Faculty of Oral \& Dental Medicine, Kafrelsheikh University, Kafr El-Sheikh, Egypt.
} 


\section{INTRODUCTION}

The state of edentulism can be restricting to the patients and has a negative influence on the quality of life. ${ }^{1}$ As usual, the conventional complete denture prostheses were the only solution for restoring edentulous patients. With the revolution of dental implantology, it gives great opportunities for full mouth rehabilitation. ${ }^{2}$

The use of dental implants progresses the oral rehabilitation of edentulous patients while using a removable or fixed dental prosthesis. Determining between fixed and removable prosthesis can be influenced by many factors such as the inter-arch space existing and relationship, intra-foraminal space, cost and patient's favorite. ${ }^{3}$ The implant supported overdentures are nowadays considered a regular treatment of choice in an edentulous arch. ${ }^{4}$

As they are considered less complex, financially reasonable and less invasive with more expectable and acceptable results in patients complaining of stability and retention with conventional dentures. ${ }^{3}$

On the other hand, Full-arch screw-retained implant-supported fixed dental prostheses are commonly used in implant treatment for edentulous patients and have established a high long-term success rate. ${ }^{5}$

When assessing treatment with implants we should consider both the clinician and the patient assessment. Concerning the clinicians, the most important factors are the implant survival, durability and the complications rate of prosthesis. To define the survival of an implant prosthesis it is better to reference "time to retreatment". 6

There are two forms of complications in implant prosthesis: biologic and technical complications. Biologic complications refer to disorders in implant function that disturb the supporting peri-implant tissues. These complications consist of early and late implant failures and contrary reactions in the peri-implant hard and soft tissues. Technical com- plications refer to mechanical injury of the implant, implant parts, and superstructures. ${ }^{7}$ Moreover, prosthetic complications after the insertion of the final prosthesis may or may not lead to implant loss but can result in an increased requirement for repair and maintenance. ${ }^{8}$

In healthy peri- implant tissue, there may be an increase of probing pocket depth (PPD) overtime $(\geq 4 \mathrm{~mm})$, with no bone loss or disease. Similarly, acute inflammation in the peri-implant mucosa is not always indicated by bleeding on probing. ${ }^{9}$

Many biomarkers such as cytokines, proteins, and multifunctional peptides can be analyzed in periimplant crevicular fluid (PICF). These biomarkers modify many immunologically-driven processes occur during early bone healing which could be related predominantly to osteoconduction. ${ }^{10}$

Many systematic reviews aggregated data about PICF for specific markers to develop early diagnostic techniques for peri-implant disease which are related to pathologic processes and associated with bone repair, inflammation, and implantation..$^{11-13}$

Moreover, several studies concentrated on the sulcus fluid analysis of many mediators, such as elastase, gelatinase, and collagenase activity, ${ }^{14}$ and proinflammatory mediators including interleukin1 beta (Il-1 $\beta$ ) and prostaglandin $\mathrm{E}_{2}\left(\mathrm{PGE}_{2}\right) .{ }^{15}$

$\mathrm{PGE}_{2}$ is one of the important inflammatory mediators which is involved in the pathogenesis of periodontal disease by decreasing the collagen synthesis and stimulating osteoclastic bone resorption. $\mathrm{PGE}_{2}$ is produced in a significant amount in the diseased periodontal tissues, while $\mathrm{PGE}_{2}$ levels are lowered after treatment. ${ }^{16}$

The aim of this study was therefore to compare the prosthetic maintenance requirements between implant-retained ball overdentures versus fixed screw- retained implant prosthesis. Clinical and radiographic changes in peri-implant tissue with using $\mathrm{PGE}_{2}$ as a PICF biomarker were also evaluated. 
According to the knowledge of the authors, there were limited studies to date that compared the fixed and removable restorations according to the maintenance and peri-implant clinical and radiographical changes.

\section{MATERIALS AND METHODS}

This study was a randomized clinical trial (RCT) carried on patients presented on the outpatient clinic in Prosthodontics Department, Faculty of Oral and Dental Medicine, kafrelsheikh university, Egypt. The study was approved by the research ethical committee of Faculty of Oral and Dental Medicine, kafrelsheikh university (KD/02/20).

\section{Sample size}

Group sample sizes of 27 and 27 produce a two-sided $80 \%$ confidence interval for the ratio of population proportions with a width that is equal to 0.896 when the estimated sample proportion 1 is 0.61 , the estimated sample proportion 2 is 0.46 , and the ratio of the sample proportions is 1.33 ,the sample size estimation was based on the previous researches where the good outcome was $46 \%$ for group I (implant-retained ball overdentures) and (61\% for group II (screw retained restorations).

\section{Trial design}

Parallel group, two arms, RCT with 1:1 allocation ratios.

\section{Selection criteria}

The inclusion criteria were (1)Completely edentulous patients have Angle Class I maxillamandibular relationship. (2) Age range between 40 and 70. (3) Maxillary and mandibular ridges with no history of fresh extraction. (4) Sufficient bone volume to house four implants in each arch. (5) Sufficient zone of keratinized attached mucosa $>5 \mathrm{~mm}$ over the crest of the upper and lower ridges. The exclusion criteria were (1) the patients have a past history of head and neck radiation ;2) previous ridge augmentation or grafting; (3) Lack of any systemic diseases that could affect osseointegration of implants as uncontrolled diabetes, hypertension, and osteoporosis; (4) Heavy smokers who exceeding 20 cigarette/ day; (5) para-functional habits for example bruxism or clenching.

\section{Patient examination}

To determine that the patients were meeting the inclusion criteria; a preliminary evaluation was done. This evaluation included a medical history form, a clinical assessment, a radiographic examination (panorama and cone beam). The main parts and procedure was discussed with participants. If they agree to share in trial, written consent obtained from them. Arabic versions of consent prepared for better participant's communication.

\section{Interventions and study procedures}

\section{Patient grouping (randomization process)}

Patients were randomly allocated to one of two parallel groups, in 1:1 ratio, to receive either ball retained implant overdentures (group I), or screw retained restoration (group II). The method used to make the random allocation sequence of the participants was a computer-generated list of random numbers using a research randomizer (https://www.randomizer.org/). The current study was a single blinded (Data analyst). The operator and patient are not blinded. Only the statistician was blind. This clinical trial was registered under a clinical trial registration number: NCT04708132.

\section{Surgical and prosthetic procedures}

\section{Surgical Procedures}

A radiopaque radiographic stent was formed by mixing autopolymerized resin (Acrostone dental company - Egypt.) with barium sulphate powder (Elnasr pharmaceutical chemicals company- Egypt) in a relationship 4:1. The stents with putty silicone index were positioned in the patient's mouth during 
cone beam CT scanning (i-CAT 17-19-Imaging Sciences International, Hatfield- PA- USA). The resulting image was found as DICOM (digital imaging and communications in medicine) data which was introduced to mimics 10.01 software where virtual planning of the implants was done. Four implants were planned with two virtual replicas, diameter of each implant was $3.75 \mathrm{~mm}$ and length was $12 \mathrm{~mm}$ for anterior and $10 \mathrm{~mm}$ for posterior implants. The planned implant sites were in the place of the lateral incisor and the second premolar. When the location of the virtual implants was accepted, the virtual surgical guides were planned on the software with four holes identical to the position of the implant.

The stent was fabricated by using rapid prototyping machine at the Central Metallurgical Research and Developing Institute. The technique used for prototyping was a selective laser sintering where the stent was manufactured layer by layer by using polyetheretherketone material. The surgical stents were tested inside the patient's mouth for fitness and stability. Three screws were used in the fixation process of each stent, one of them in the midline and two at the area of the first molar bilaterally.

The osteotomy was carried out by using three consecutive drills at increased diameter of 2.2, 2.8 and $3.5 \mathrm{~mm}$. respectively fig:(1). Once all implants (Dentis Co., Ltd, South Korea) were installed, both the fixation screws and the stents were removed. After that, the covering screw was then screwed over the implant fixture. The post-operative treatment was composed of Prophylactic antibiotic was prescribed for all patients; the required dose is a capsule every eight hour of $500 \mathrm{gm}$ amoxicilline (Misr Company-pharmaceutical industries- October Pharma S.A.E. Egypt)

In addition, for the next 5 days, analgesic drug (Ibuprofen 600mg- Knoll AG-LudwigshafenGermany) was given once daily or when needed.

\section{Prosthetic Procedures}

Once the healing period of four months finished, the patients were recalled. By administration of local anesthesia, the implants were exposed by using the lancet, and the position of the implants was determined by using the surgical stent. The covering screws are unscrewed by using a screwdriver.

\section{Regarding the group of implants supported over denture}

The ball attachments with 2.5 diameters were screwed on each implant after removal of the cover screw fig:(2). Regarding the pickup of the ball, a hole was cut in the fitting surface opposing to the site of each implant. The metal caps were inserted over each ball attachment by using the autopolymer acrylic resin for metal cap pick up, a rubber dam located around the ball attachment for block out, and the patient was requested to occlude in a centric relation. After complete polymerization of the acrylic resin, the dentures were removed from the patient's mouth and examined. After that, the occlusion was checked and re-adjusted.

\section{Regarding the screw retained restoration}

After removal of the cover screw, the permanent transmucosal titanium abutments (Transmucosal Octa abutment- DENTIS-Korea) were attached over the implant fixtures and torqued to $35 \mathrm{Ncm}$ by using the torque ratchet. Secondary impression was made by using rubber base (Putty and light consistency silicone- elite HD+- Zhermack- Italy) by using an open tray impression technique. The master casts were tested for accuracy by using an acrylic verification jig. The verification jig was tested intraorally for checking the passivity fig:(3). If the verification jig was not passively seated; it was sectioned and reassembled by using duralay resin (Duralay- Low shrink self-cure acrylic resinReliance Dental Manufacturing Company, Chicago, USA), and a new cast was constructed. 
The occlusion blocks were made for a new bite registration record. After that, the artificial setup of teeth was done and the try-in was completed. A putty index was made for the facial and occlusal surfaces of the teeth. Concerning the screw retained restorations, plastic burnout cylinders (Dentis s-clean subocta system- burnout plastic octa cylinder- Korea) were attached to the implant analogues and were connected together by using duralay resin. Above the duralay frame structure, a wax pattern was fabricated, sprued, invested, and casted into chrome cobalt alloy. An opaquer was painted to the framework and light cured. The artificial teeth (Viso-lign Light Cured Vennering Composite Resin, Germany) were then sited in place by using the putty index and attached to the framework by using light cure. Gingival composite material was added, and light cured. Finally, the final prosthesis was finished and polished. The occlusal adjustments were performed by using articulating paper. After that, the prosthetic screws were tightened to $25 \mathrm{Ncm}$ with a torque wrench. The access hole was partially locked with pink wax (Cavex Set Up Modelling Wax- Holland BV) and totally blocked with light cured composite resin restoration (Super-Cor ${ }^{\mathrm{TM}}$ - SpofaDental- Czech Republic) fig:(4).

\section{Follow-up}

During the 12-month follow-up period, prosthodontic complications for the implant-Supported ball overdentures and the screw- retained restorations were recorded and calculated. Prosthodontic maintenance and complications were divided according to prosthetic restoration type and implant components and recorded by frequency of each event in both groups.

Along with a conventional oral hygiene assessment and functional check-up, clinical soft tissue measurements which include plaque index (PI), gingival index (GI) using Mombelli indices, ${ }^{17}$ and PPD were measured at the mid-facial, mid- lingual, mid-mesial, and mid-distal aspects of each fixture using a graduated plastic probe to the nearest $0.5 \mathrm{~mm}$. The clinical measurements were recorded after prosthesis delivery, 6- and 12-months postoperatively. Intra-examiner reproducibility was evaluated with a calibration exercise performed on two distinct occasions, 48 hours apart. Calibration was accepted if $\geq 90 \%$ of the recordings could be reproduced within a difference of $1.0 \mathrm{~mm}$.

The peri-implant marginal bone loss (MBL) was assessed and calculated radiographically using the Digora system after prosthesis delivery, 6 and 12 months postoperatively. The distance between the crestal bone level and the most apical boneimplant interface was calculated in $(\mathrm{mm})$ with the aid of periapical radiographs (Digital Intraoral Sensor-Digora) using the long cone technique. Measurement of bone loss was done with the help of the same measurement tools to ensure reproducibility between follow-up, radiographs were made using the paralleling technique. A specific holder (FPS 3000 Holder-Made in China) was utilized to maintain the film position accurately each time. The holder was prepared to receive the impression coping and held securely by the fixation done through the screwdriver and the film holder. The images were manipulated by using the software by calibrating the implant length and width through the insertion of the actual implant length $(\mathrm{mm})$. A vertical straight line was drawn from the implant shoulder to the most apical part of the fixture, and a horizontal straight line was drawn from the mesial to the distal aspect of the implant shoulder.

\section{Collection of peri-implant crevicular fluid (PICF) samples}

PICF was collected using the method reported by Wilson et al. ${ }^{18}$ after prosthesis delivery, 6 and 12 months postoperatively. After isolation and drying of the test site, pre-sterilized filter paper strips (Whatman filter Paper) ${ }^{19}$ were inserted $2 \mathrm{~mm}$ into 
the peri-implant sulcus for 60 seconds. The strip was placed in a sterile micro-centrifuge tube, frozen and stored at $-80^{\circ} \mathrm{C}$ until its use. Strips contaminated with blood were discarded.

\section{Data collection and analysis}

Data were collected, tabulated and statistically analyzed using statistical analysis software SPSS (SPSS: Statistical Packages for the Social Sciences, IBM, USA) version 25 for mac, the mean, standard deviation (SD), and percentage were calculated for several variables, Kolmogorov-Smirnov was used to evaluate the normal distribution. For parametric variables, ANOVA test was used in case of more than two variables, Tukey post hoc tests were used in case of significance, t-test was used for two independent groups, continuous variables, the Chisquare test was used for categorical variables. The degree of statistical significance was considered $<0.05$

\section{RESULTS}

In the present study 27 patients were included in ball retained implant overdentures (group I), and 27 patients were included in screw retained restoration (group II). After the 12-month follow-up period, the results obtained from this study were tabulated and statistically analyzed.

Regarding the Prevalence of complications according to the type of prosthesis, in group I: the result of this study showed that acrylic tooth fracture in Ball retained over denture occurred 3 times with a percentage of $(11.11 \%)$. The fracture/ damage of acrylic parts and the Acrylic relining occurred one time with a percentage of (3.7\%). Regarding the prosthetic complications in ball retained overdenture group, the acrylic tooth fracture showed the highest rate of complication $(11.11 \%)$ during the follow up period. In group II: The result of this study showed that acrylic tooth fracture in screw retained restoration occurred 5 times with a percentage of $(18.52 \%)$. The fracture or damage of acrylic parts, the screw loosening of the prosthesis, and new prosthesis construction occurred one time with a percentage of $(3.7 \%)$. Regarding the prosthetic complications in the screw retained restoration group, the acrylic tooth fracture showed the highest rate of complication (18.52\%) during the follow-up period. The result of this study revealed that there was no statistically significance difference between screw retained restorations (Fixed) and ball retained over denture (Removable) regarding the frequency of maintenance of prosthetic parts of both type of restorations $(\mathrm{P}=0.34)$ table (1) fig (5).

Regarding the prevalence of complications related to the Implant components, in group I, the result of this study showed that the female part loose in ball retained overdenture occurred 2 times with a percentage of $(7.4 \%)$. The female part deformation/ worn out occurred one time with a percentage of (3.7\%). Loosening of the abutment occurred two times with a percentage of $(7.4 \%)$. Re-activation of attachments and replacement with new components occurred three times with a percentage of (11.11\%). Regarding the maintenance of implant components in ball retained overdenture group, the need for new components and re-activation of attachments showed the highest rate of complication (11.11\%) during the follow-up period. In group II, the result of this study showed that the screw loosening in screw retained restoration occurred 1 time during the follow-up period with a percentage of $(3.7 \%)$. The result of this study revealed that there was a statistically significance difference between screw retained restorations (Fixed) and ball retained over denture (Removable) regarding the frequency of maintenance of implant components of both type of restorations $(\mathrm{P}=0.001)$ table $(2)$, fig $(6)$. 
Regarding clinical and radiographic evaluation of peri implant tissues, the result of this study showed that the periodontal status of the two studied groups was demonstrated using the mean and standard deviation for the appropriate clinical measurements: PI, GI, PPD, and MBL. No statistically significant differences were found at baseline between treated sites of both groups with respect to soft and hard tissue measurements $(\mathrm{P}>.05)$. Both groups showed statistically significant increase in PI, GI, and PPD at 6 and 12 months compared with initial values. Regarding PI and GI, no significant differences were found between the 6- and 12-month observation periods $(\mathrm{P}>.05)$. For $\mathrm{PPD}$, there was a statistically significant difference between the 6- and 12-month observation periods for both groups $(\mathrm{P}<.001)$; fig (7). At 6 and 12 months, group I showed statistically significant lower mean PI, GI, and PPD compared with group II $(\mathrm{P}<.001)$; table (3). At 6 and 12 months, there was a statistically significant increase in MBL in both groups with statistically significant higher MBL for screw retained group II compared with ball retained overdenture group I $(\mathrm{P}<.001)$; table (4), fig (8).

Concerning $\mathrm{PGE}_{2}$-PICF levels, there was a significant increase after 6 months in both groups $(P<.001)$. Afterwards, $\mathrm{PGE}_{2}$-PICF levels significantly decreased after 12 months, which showed a non-significant difference from the initial value ( $P>.05$ ). Throughout all observation periods, there was no statistically significant difference between group I and group II ( $P>.05)$; table (5), fig (9).

TABLE (1): The difference between the frequency of prosthetic complications in the two studied groups during the follow up period

\begin{tabular}{|l|c|c|c|c|}
\hline & Non failed & Failed & chi square & p value \\
\cline { 1 - 4 } Group I (ball retained implant over denture, Removable) & $22(81.48 \%)$ & $5(18.52 \%)$ & & \\
\cline { 1 - 4 } Group II (screw retained restorations, Fixed) & $19(70.37 \%)$ & $8(29.63 \%)$ & & 0.34 \\
\hline
\end{tabular}

*Statistically significant at $P \leq .05$.

TABLE (2): The difference between the frequency of complications related to the implant components in the two studied groups during the follow up period

\begin{tabular}{|l|c|c|c|c|}
\hline frequency of complications related to the implant components & Non failed & Failed & chi square & p value \\
\hline Group I (ball retained implant over denture, Removable) & $16(59.26 \%)$ & $11(40.74 \%)$ & & \\
\cline { 1 - 2 } Group II (screw retained restorations, Fixed) & $26(96.30 \%)$ & $10.714 \mathrm{a}$ & $0.001^{*}$ \\
\hline
\end{tabular}

*Statistically significant at $P \leq .05$. 
TABLE (3): PI, GI, and PPD Comparison for the two studied groups during different observation periods

\begin{tabular}{|c|c|c|c|}
\hline & $\begin{array}{c}\text { Group I } \\
\text { ball retained } \\
\text { implant over } \\
\text { denture, } \\
\text { Removable) }\end{array}$ & $\begin{array}{c}\text { Group II } \\
\text { (screw retained } \\
\text { restorations, } \\
\text { Fixed) }\end{array}$ & $P$ \\
\hline \multicolumn{4}{|c|}{ Plaque index } \\
\hline Baseline & $0.56 \pm 0.51 \mathrm{c}$ & $0.63 \pm 0.49 \mathrm{c}$ & 0.588 \\
\hline 6 months & $1.3 \pm 0.54 \mathrm{~b}$ & $1.81 \pm 0.56 b$ & $0.0011^{*}$ \\
\hline 12 months & $1.56 \pm 0.51^{\mathrm{ab}}$ & $1.96 \pm 0.59 \mathrm{ab}$ & $0.0086^{*}$ \\
\hline \multicolumn{4}{|c|}{ Gingival index } \\
\hline Baseline & $0.33 \pm 0.48 \mathrm{c}$ & $0.37 \pm 0.49 \mathrm{c}$ & 0.588 \\
\hline 6 months & $0.81 \pm 0.56 b$ & $1.22 \pm 0.58 b$ & $0.0011^{*}$ \\
\hline 12 months & $1.26 \pm 0.45 \mathrm{ab}$ & $1.63 \pm 0.49 a b$ & $0.0086^{*}$ \\
\hline \multicolumn{4}{|c|}{ Probing pocket depth/ mm } \\
\hline Baseline & $0.98 \pm 0.056 \mathrm{c}$ & $1.0 \pm 0.10 \mathrm{c}$ & 0.3826 \\
\hline 6 months & $1.76 \pm 0.12 b$ & $2.44 \pm 0.18 b$ & $<0.0001^{*}$ \\
\hline \multirow[t]{2}{*}{12 months } & $2.32 \pm 0.16 \mathrm{a}$ & $2.88 \pm 0.14 \mathrm{a}$ & $<0.0001^{*}$ \\
\hline & $\boldsymbol{P}<0.0001^{*}$ & $\boldsymbol{P}<0.0001^{*}$ & \\
\hline
\end{tabular}

Different small letters within the same group indicate presence of significance

*Statistically significant at $P \leq .05$.

TABLE (4): MBL Comparison for the two studied groups during different observation periods

\begin{tabular}{|c|c|c|c|}
\hline & $\begin{array}{c}\text { Group I } \\
\text { ball retained } \\
\text { implant over } \\
\text { denture, } \\
\text { Removable) }\end{array}$ & $\begin{array}{c}\text { Group II } \\
\text { (screw retained } \\
\text { restorations, } \\
\text { Fixed) }\end{array}$ & $\boldsymbol{P}$ \\
\hline \multicolumn{4}{|c|}{ MBL/ mm } \\
\hline Baseline & $0.98 \pm 0.056 \mathrm{c}$ & $1.0 \pm 0.10 \mathrm{c}$ & 0.3826 \\
\hline 6 months & $1.76 \pm 0.12 \mathrm{~b}$ & $2.44 \pm 0.18 \mathrm{~b}$ & $<0.0001^{*}$ \\
\hline 12 months & $2.32 \pm 0.16 \mathrm{a}$ & $2.88 \pm 0.14 \mathrm{a}$ & $<0.0001^{*}$ \\
\hline & $\boldsymbol{P}<0.0001^{*}$ & $\boldsymbol{P}<0.0001^{*}$ & \\
\hline
\end{tabular}

Different small letters within the same group indicate presence of significance

*Statistically significant at $P \leq .05$.
TABLE (5): $\mathrm{PGE}_{2}$ Comparison for the two studied groups during different observation periods:

\begin{tabular}{|c|c|c|c|}
\hline & $\begin{array}{c}\text { Group I } \\
\text { ball retained } \\
\text { implant over } \\
\text { denture, } \\
\text { Removable) }\end{array}$ & $\begin{array}{c}\text { Group II } \\
\text { (screw retained } \\
\text { restorations, } \\
\text { Fixed) }\end{array}$ & $\boldsymbol{P}$ \\
\hline PGE $/ \mathbf{~ n g / m l ~}^{\mid}$ & \\
\hline Baseline & $42 \pm 6.12 \mathrm{cb}$ & $42.39 \pm 7.29 \mathrm{cb}$ & 0.85 \\
\hline 6 months & $56.59 \pm 7.23 \mathrm{a}$ & $60.4 \pm 10 \quad \mathrm{a}$ & 0.114 \\
\hline 12 months & $46.53 \pm 7.65 \mathrm{~b}$ & $2.88 \pm 0.14 \mathrm{~b}$ & $<0.0001^{*}$ \\
\hline & $\boldsymbol{P}<0.0001^{*}$ & $\boldsymbol{P}<0.0001^{*}$ & \\
\hline
\end{tabular}

Different small letters within the same group indicate presence of significance

*Statistically significant at $P \leq .05$.

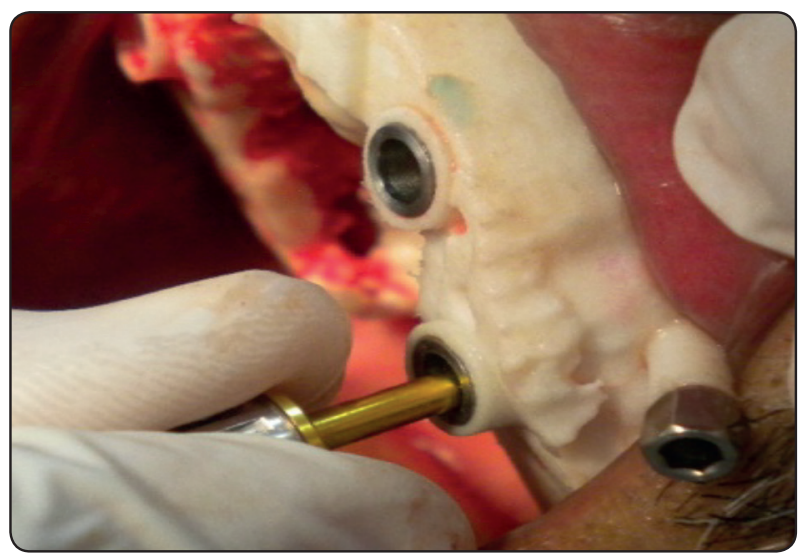

Fig. (1): Computer guided stent in place and tighten the implant with screw driver

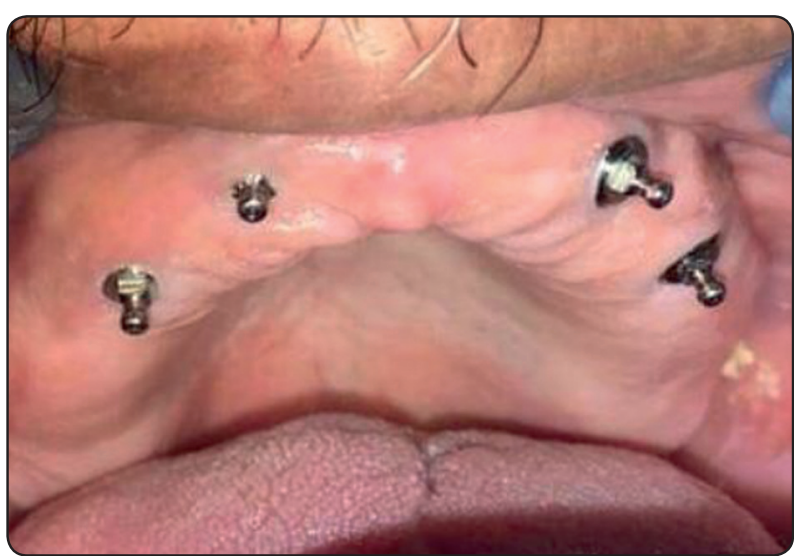

Fig. (2): Ball attachment in place after healing period 


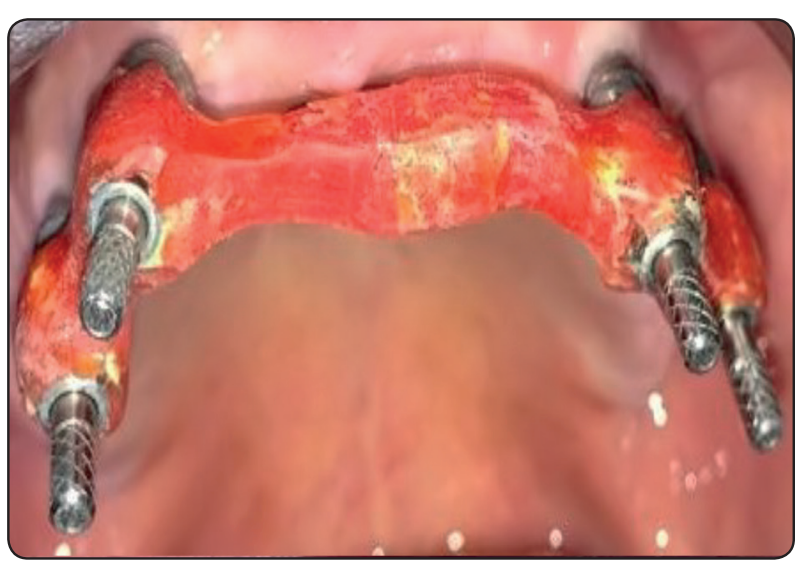

Fig. (3): Check the Verification jig intra orally

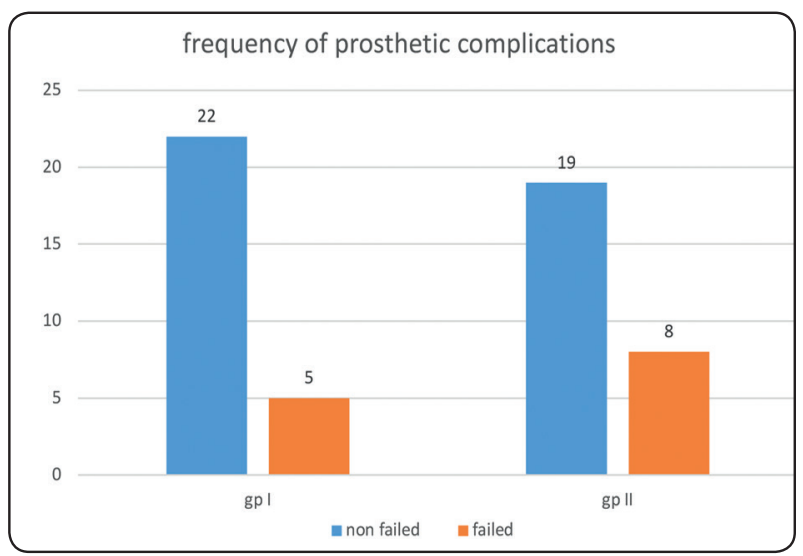

Fig. (5): Bar chart representing mean and standard deviation of frequency of prosthetic complications in both in the two studied groups:

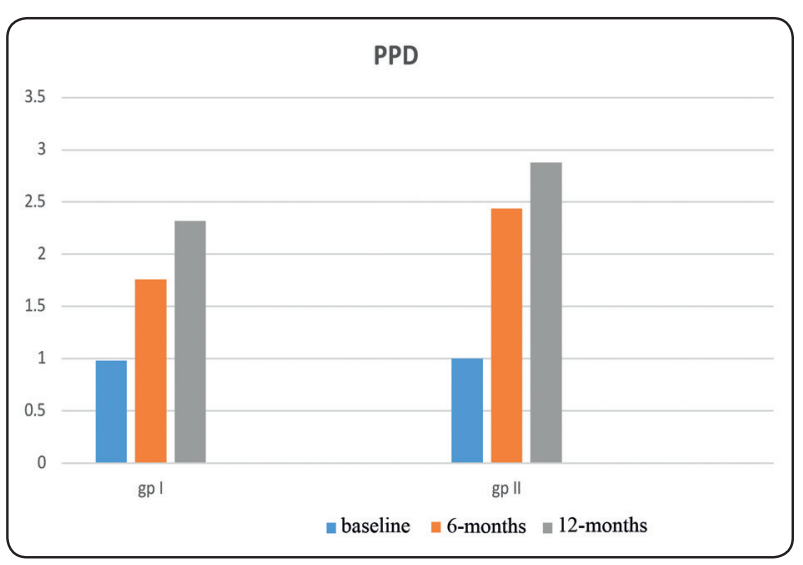

Fig. (7): Bar chart representing mean and standard deviation of PPD in the two studied groups:

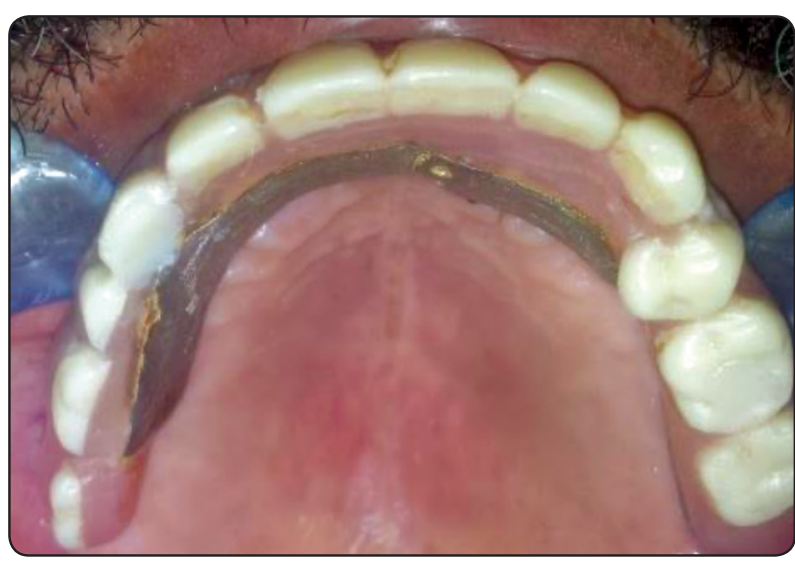

Fig. (4): Maxillary Final screw retained restoration in place during the follow up period

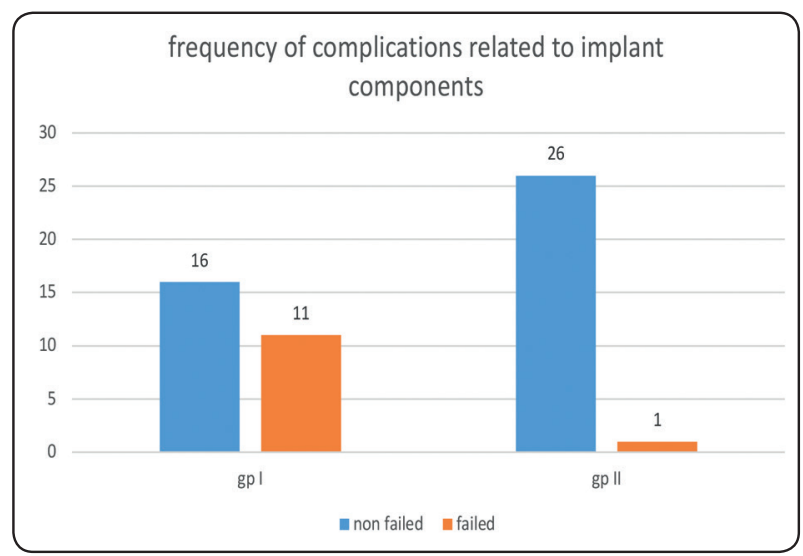

Fig (6): Bar chart representing mean and standard deviation of frequency of complications related to the implant components in the two studied groups:

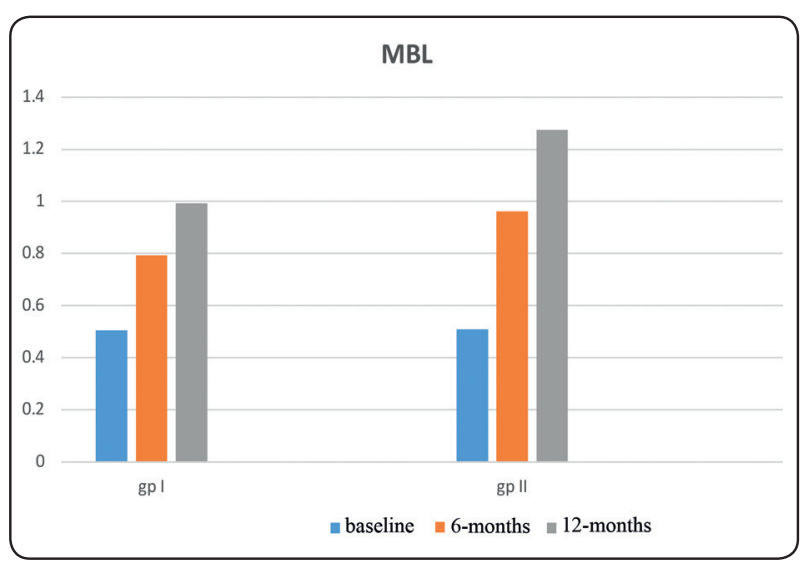

Fig. (8): Bar chart representing mean and standard deviation of MBL in the two studied groups: 


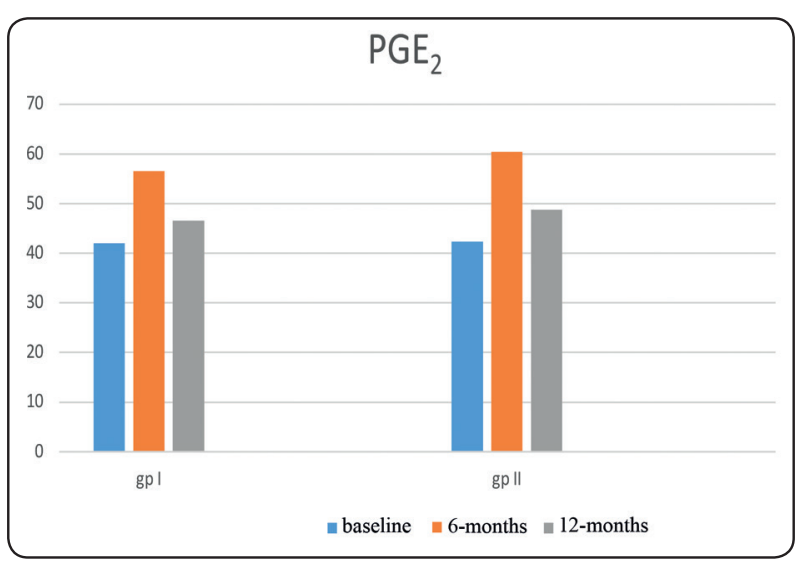

Fig. (9): Bar chart representing mean and standard deviation of PGE2 in the two studied groups

\section{DISCUSSION}

The present study was established to compare the maintenance requirements between implantSupported ball overdentures versus fixed screwretained implant prosthesis.Clinical and radiographic changes in peri-implant tissue with using $\mathrm{PGE}_{2}$ as a PICF biomarker were also evaluated.

A follow-up of 12 months was selected in the present study according to Johansson and Palmqvist, ${ }^{20}$ as earlier studies have shown that prosthodontic complications happen both during the first year after treatment and in the long term, though it was reported that the rate of complications reduces over time.

Regarding the frequency of maintenance of prosthetic parts: the result of this study revealed that there was no statistically significance difference between screw retained restorations and ball retained overdenture regarding the frequency of maintenance of prosthetic parts of both types of restorations $(p=0.34)$. Although, the acrylic tooth fracture showed the highest rate of complication in both groups, $(11.11 \%)$ in ball retained overdenture and $(18.52 \%)$ in screw retained restoration group during the follow-up period. Comparably, McGlumphy et al. ${ }^{21}$ found that the most common complication in metal-acrylic resin implant complete fixed dental prosthesis MRFCDs (fixed restoration) was the fracture of teeth which was noted in $45.8 \%$ of patients. In addition, the fracture of teeth was reported in $44.6 \%$ of patients in the maxillary complete denture CRDPs (removable prosthesis). The fractured teeth were changed in the lab. All teeth fractures happened in the anterior region following to the lateral incisor and canine area. The acrylic teeth fracture may be due to inadequate space for the teeth due to thick metal abutments in the anterior teeth and deficient thickness of acrylic resin. As increase of acrylic resin in this area will result in lip bulging and affect aesthetics.

Moreover, Jemt and Johansson ${ }^{22}$ reported that tooth fracture and wear were the most frequent complications in a 15-year follow-up. Attard and Zarb ${ }^{23}$ in 20-year follow-up reported the screw fracture, tooth wear, and tooth fracture as the most common prosthetic complications with the fixed screw retained restorations. Similarly, a systematic review ${ }^{24}$ which reported that fixed implant prosthesis presented with a variable rate of different complications, as veneer fracture being the most common one. Veneer fractures may be due to material failure, design problems such as lack of passive fit or insufficient prosthetic space or excessive cantilevers and/or technical mistakes. ${ }^{25}$

On the other hand , McGlumphy et al. ${ }^{21}$ reported that the screw complications were the second most frequently seen problem. In the current study, the screw loosening of the abutment occurred in the fixed screw retained restoration group with a percentage of $(3.7 \%)$. Many factors may cause screw complications such as deficient preload on the screws, over tightening of the screws may cause stripping and/or screw distortion and/or excessive occlusal load from parafunction, occlusal interferences, or exceedingly long cantilevers. ${ }^{26}$

Furthermore, the result of this study is comparable to the results of McGlumphy et al. as reported that the fractured implant-prosthetic components have 
been a problem for both clinicians and patients. In addition, McGlumphy et al. reported that the screw fracture and loosening were the most common screw complications. ${ }^{21}$ In different situations, the screw loosening was observed, not only by the patients, but also by the regulated hygienists during yearly hygiene visits when the prostheses were removed.

In the present study, new prosthesis construction occurred one time with a percentage of $(3.7 \%)$ this is comparable to the study of Ibrahim et al..$^{27}$ as they reported that remake of the prosthesis happened twice in the fixed group only due to fracture of the prosthesis. Fracture of the prosthesis may be due to defective design of the metal framework which was modified by the adding of retentive undercuts in the form of beads on the surface of the framework.

The framework fracture happened in two patients $(8.3 \%)$ in the present study. One of these fractures resulted in fabrication of a new prosthesis. Both fractures happened for frameworks made of type III gold alloy; however, it should be noted that type III gold alloy was not used for the three of the frameworks in the current study.

Regarding the maintenance of implant components, the result of this study revealed that there is a statistically significance difference between screw retained restorations (Fixed) and ball retained over denture (Removable) regarding the frequency of maintenance of implant components of both type of restorations $(\mathrm{P}=0.001)$.

In addition, the need for new components and re-activation of attachments in ball retained over denture group showed the highest rate of complication $(11.11 \%)$ during the follow-up period.

Similarly, Ma et al. ${ }^{28}$ reported that the most frequent prosthodontic maintenance issue for implant-supported ODs is related to the matrixpatrix complex and needs for prosthodontic maintenance have been stated as direct consequences of the attachment system. ${ }^{29}$
Though, it is difficult to expect the change cycle of the matrix or O-rings since this may be influenced by factors relating to the patients and operators. ${ }^{30}$

The increased need for maintenance with ball attachment may be due to the presence of an increased rotational axis. ${ }^{31}$ Therefore, the hinging overdenture may be often rebased to attain a stable position in posterior jaw areas, where resorption may happen. ${ }^{32}$

In addition, a study that compared the maintenance requirements of overdentures retained by ball attachments with that of screw- retained prosthesis reported that patients needed more appointments in the removable group both in the first year and beyond with $23 \%$ demanding more than 5 appointments per year, in contrast to $5 \%$ of the patients in the fixe group. Concerning the prosthesis, the frequency of remakes, relines and general adjustments was higher in the removable group. ${ }^{33}$

Although , solitary attachments were frequently reported to be easier to maintain or repair than splinted attachments. ${ }^{34}$ Then, it is hard to conclude that the use of a specific attachment is superior to others for maintenance. Then, the use of components that are easy to operate and cost-effective could be chosen as attractive treatment choices for both the operators and patients. In addition, balls are considered to be the easiest and most cost-effective type of attachment for clinical application..$^{35}$

In conclusion, there are several factors that should be considered when determining whether a fixed or removable implant-supported complete denture or overdentures is the best option for rehabilitation of completely edentulous patients. From the previous studies, bone atrophy is considered to be one of the most important decisional criteria. This is due to the demand to support facial soft tissue, in addition to providing proper hygiene maintenance. Additionally, fixed/removable treatment options represent a resilient system against occlusal force, decreasing the overall number of complications..$^{36,37}$ 
Regarding clinical and radiographic evaluation of peri implant tissues, the dental implants are functionally stable and have long-term success rates. Thus, they have widely been used in the oral rehabilitation of partially and completely edentulous individuals. Nevertheless, the incidence of inflammation around a dental implant has increased with the growing number of patients receiving dental implants. ${ }^{38}$ Adequate zone of keratinized mucosa was recommended to ensuring the maintenance of the peri-implant tissue health with no gingival recession around implants, especially in the early phase after prosthetic therapy. ${ }^{39}$

Clinical peri-implant evaluation is necessary for the detection of early biological complications of the implants. Appropriate clinical parameters and indices are available which can determine the inflammatory response in the peri-implant hard and soft tissues. ${ }^{40}$ Analyses of the constituents of PICF may provide crucial information about the inflammatory processes around dental implants. $\mathrm{PGE}_{2}$ had been studied for the detection of the inflammation around dental implants ${ }^{41}$ Filter paper was used for GCF sampling as it is the easiest and more precise method for GCF collection. ${ }^{42}$

The current study displayed non-significant differences in all of the clinical parameters for both groups at baseline, this confirmed equivalent treatment outcomes during the follow-up periods. At 6 and 12 months, group II reported significantly higher PI and GI compared with group I. This was in accordance with Stocker et al.$^{43}$ who stated that the patients with the bar attachments have significantly higher PI than those with ball attachments. Costa et al ${ }^{44}$ also revealed significantly worse peri-implant biological conditions for the fixed restoration group compared with the removable overdenture group. This could be attributed to the larger surface of the metal supra structure that is exposed in the mouth and the lack of cleaning of the screw retained group which may lead to increased plaque accumulation, increased mucosal inflammation and bleeding on probing. ${ }^{45}$ Similarly, group I showed a significantly lower PPD than group II, a result that supports previous finding of more PPD in the bar attachment group than other solitary attachment groups. ${ }^{46}$ Deep pockets could be explained by a gingival hyperplasia under the rigid bar, and thus representing partially pseudo-pockets. But the significant correlation between maximal PPD and MBL occurred in both groups. This means that PPD might be an important clinical instrument to evaluate the performance of implants.

The success of dental implant treatment mainly depends on the sustainable long-term health of soft and hard peri-implant tissues. This can be assessed by specific criteria which include mobility, pain, infection, inflammation and MBL at the peri-implant surfaces which should not exceed 1-2mm during the first year of function and $0.2 \mathrm{~mm}$ thereafter. ${ }^{47,48}$ Based on these criteria, all MBL in both designs was within the acceptable values for implant success. But the results significantly revealed less MBL at the ball retained overdenture group I than at the screw retained group II. A similar observation was also noted in other studies. ${ }^{49,50}$

The immunologic investigation method provides comprehensive information regarding the current status, prognosis and treatment course of loaded implants as well as the analysis of patient responses to inflammatory disease. In both groups, $\mathrm{PGE}_{2}$ levels were significantly increased after 6 months. This could be explained that the possible exposure of the soft tissues to a portion of the seating platform in both groups may contribute to higher levels of initial inflammatory response in the initial period. Then, it was significantly decreased after 12 months with a non-significant difference from the baseline. This is in accordance with Dellavia et al. ${ }^{51}$ who reported that, after prolonged exposure of abutments in the oral cavity, the configuration of the implant abutment interface does not seem to affect the inflammatory cellular and molecular pattern responsible for bone loss. 


\section{CONCLUSIONS}

Within the limitation of this study, the following conclusions were drawn from the results of the present one-year follow-up clinical evaluation:

The type of prosthesis either fixed screw retained restorations (fixed prosthesis) or ball retained over denture (removable prosthesis) have relatively the same influence on the frequency of maintenance of prosthetic parts of each type of prosthesis. Although, the fixed screw retained restorations showed lower rate of maintenance of implant components than ball retained over denture. Furthermore, the fixed screw retained restoration was more vulnerable than the ball retained over denture with respect to maintaining peri-implant tissue health.

\section{ACKNOWLEDGMENTS}

The authors reported no conflict of interest related to this work.

\section{REFERENCES}

1. Strassburger C, Kerschbaum T and Heydecke G. Influence of implant and conventional prostheses on satisfaction and quality of life: A literature review. Part 2: Qualitative analysis and evaluation of the studies. Int J Prosthodont. 2006; 19:339-348.

2. Turbush S. and Turkyilmaz I. Accuracy of three different types of stereolithographic surgical guide in implant placement: an in vitro study. J Prosthet Dent. 2012; 3: 181-188.

3. Delben JA, Lima J, Cabral T, Assunc WG, Barao VR. Com $\neg$ parison of different designs of implant-retained overden $\neg$ tures and fixed full-arch implant-supported prosthesis on stress distribution in edentulous mandible-A computed tomography-based three-dimensional finite element analysis. J Biomech. 2013; 46:1312-1320.

4. Kern JS, Kern T, Wolfart S, Heussen N. A systematic review and meta-analysis of removable and fixed implantsupported prostheses in edentulous jaws: post-loading implant loss. J Clin oral imp Research. 2013; 2:174-195.

5. Engstrand, P., Gröndahl, K., Ohrnell, L.-O., Nilsson, P., Nannmark, U., \& Brånemark, P.-I. (2003). Prospective follow-up study of 95 patients with edentulous mandibles treated according to the Brånemark Novum concept. J Clin Implant Dent Relat Res.2003; 5: 3-10.

6. Carr AB. Successful long-term treatment outcomes in the field of osseointegrated implants: prosthodontic determinants. Int J Prosthodont .1998;11:502-12.

7. Berglundh T, Persson L, Klinge B. A systematic review of the incidence of biological and technical complications in implant dentistry reported in prospective longitudinal studies of at least 5 years. J Clin Periodontol .2002;29:197-212.

8. Papaspyridakos, P., Chen, C. J., Chuang, S. K., Weber, H. P., \& Gallucci, G. O. A systematic review of biologic and technical complications with fixed implant rehabilitations for edentulous patients. Int $\mathbf{J}$ Oral Maxillofac Implants .2011; 2:102- 110

9. Coli, P., Christiaens, V., Sennerby, L., \& Bruyn, H. D. Reliability of periodontal diagnostic tools for monitoring peri-implant health and disease. J Periodontol 2000. 2017;73:203-217.

10. Trindade, R., Albrektsson, T., \& Wennerberg, A. Current concepts for the bio- logical basis of dental implants: Foreign body equilibrium and osseointegration dynamics. J Oral Maxillofac Surg Clinics N America. 2015b; 27:175-183.

11. Duarte, P. M., Serrão, C. R., Miranda, T. S., Zanatta, L. C. S. S., Bastos, M. F., Faveri, M., et al. Could cytokine levels in the peri-implant crevicular fluid be used to distinguish between healthy implants and implants with periimplantitis? A systematic review. J Periodontal Res. 2016; 51:689-698.

12. Faot, F., Nascimento, G. G., Bielemann, A. M., Campão, T. D., Leite, F. R. M., \& Quirynen, M. Can peri-implant crevicular fluid assist in the diagnosis of peri-implantitis? A systematic review and meta-analysis. J Periodontol. 2015; 86:631-645.

13. Kaklamanos, E. G., \& Tsalikis, L. A review on peri-implant crevicular fluid assays potential in monitoring and predicting peri-implant tissue responses. J Int Acad Periodontol. 2002;4: 49-59.

14. Giannopoulou C, Bernard JP, Buser d, Carrel A, Belser uC. Effect of intracrevicular restoration margins on periimplant health: Clinical, biochemical and microbiological findings around esthetic implants up to 9 years. Int $\mathbf{J}$ oral Maxillofac Implants .2003; 18:173-181

15. Lachmann S, Kimmerle- Müller E, Gehring K, Axmann D, Gomez- Roman G, Watzek G, Weber H. A comparison 
of implant- supported, bar- or bar- retained mandibular overdentures: a retrospective clinical, microbiologic, and immunologic study of 10 edentulous patients attending a recall visit. Int J Prosth. 2007;2: 37-42.

16. Vardar-Sengûl S, Baylas H, Huseyinov A. Effect of selective cyclooxygenase-2 inhibition on gingival tissue levels of prostaglandin E2 and prostaglandin F2á and clinical parameters of chronic periodontitis. J Periodontol .2003; 74: 57-63.

17. Mombelli A, van Oosten MA, Schurch E, Jr., Land NP. The microbiota associated with successful or failing os- seointegrated titanium implants. J Oral Microbiol Immunol. 1987; 2:145-51.

18. Wilson AN, Shmidt MJ, Marx DB, Reinhardt RA. Bone turnover markers in serum and periodontal microenvironments. J Periodontal Res. 2003; 38:355-361

19. Griffiths GS, Curtis MA, Wilton JM. Selection of a filter paper with optimum properties for the collection of gingival crevicular fluid. J Periodont Res. 1988; 23:33-38.

20. Johansson G, Palmqvist. S. Complications, maintenance in edentulous arches with implant-supported fixed supplementary treatment, and prostheses. Int J Prosthodont. 1990; 3:89-92.

21. McGlumphy EA, Hashemzadeh S, Yilmaz B, Purcell BA, Leach D, Larsen PE. Treatment of edentulous mandible with metal-resin fixed complete dentures: A 15- to 20-year retrospective study. J Clin Oral Implants Res. 2019; 30:817-25.

22. Jemt, T., \& Johansson, J. Implant treatment in the edentulous max- illae: A 15-year follow-up study on 76 consecutive patients provided with fixed prostheses. J Clin Implant Dent Relat Res.2006; 8:61-69

23. Attard NJ, Zarb GA. Long-term treatment outcomes in edentulous patients with implant-fixed prosthesis: The Toronto study. Int J Prosthodont. 2004; 17:417-424.

24. Torbjo rner A. Fransson B. Biomechanical aspects of prosthetic treatment of structurally compromised teeth. Int J Prosthodont. 2004;17: 135- 41.

25. Goodacre CJ, Bernal G, Rungcharassaeng K, Kan JY. Clinical complications with implants and implant prostheses. J Prosthet Dent .2003; 90:121-32.

26. McGlumphy EA, Mendel DA, Holloway JA. Implant screw mechanics. J Dent Clin North Am. 1998; 42:71-89.

27. Ibrahim W, Kaddah A, ElKhadem A. Maintenance Re- quirements of Screw-Retained Implant Prosthesis versus Telescopic Overdenture: A Randomized Controlled Trial. IJSR. 2016; 12: 2319-7064

28. Ma S, Waddell JN, Atieh MA, Alsabeeha NH, Payne AG .Maxillary three-implant overdentures opposing mandibular two-implant overdentures: 10-year prosthodontic outcomes. Int J Prosthodont .2016;29: 327-336.

29. Osman, R. B., Payne, A. G., \& Ma, S. Prosthodontic maintenance of maxillary implant overdentures : A systematic literature review. Int J Prosthodont.2012;25: 381-391.

30. Payne, A. G., \& Solomons, Y. F. The prosthodontic maintenance requirements of mandibular mucosa- and implantsupported overdentures: A review of the literature. Int $\mathrm{J}$ Prosthodont.2000; 13: 238-243.

31. Kimoto S, Pan S, Drolet N, Feine JS. Rotational movements of mandibular two-implant overdentures. J Clin Oral Implants Res. 2009; 20:838-43.

32. Kordatzis K, Wright PS, Meijer HJ. Posterior mandibular residual ridge resorption in patients with conventional dentures and implant overdentures. Int J Oral Maxillofac Implants. 2003; 18:447-52.

33. Tinsley D, Watson CJ, Russell JL. A comparison of hydroxylapatite coated implant retained fixed and removable mandibular prostheses over 4 to 6 years. J Clin Oral Implants Res. 2001; 12:159-66.

34. Cavallaro, J. S. Jr, \& Tarnow, D. P. Unsplinted implants retain- ing maxillary overdentures with partial palatal coverage: Report of 5 consecutive cases. Int J Oral Maxillofac Implants .2007;22:808-814.

35. Cakarer S, Can T, Yaltirik M, Keskin C . Complications associated with the ball, bar and Locator attachments for implant-supported overdentures. J Med Oral Patol Oral Cir Bucal .2011;16: e953-959.

36. Avrampou, M.; Mericske-Stern, R.; Blatz, M.B.; Katsoulis, J. Virtual implant planning in the edentulous maxilla: Criteria for decision making of prosthesis design. J Clin Oral Implant Res. 2012; 24:152-159.

37. Zitzmann, N.U.; Marinello, C.P. Fixed or removable implant-supported restorations in the edentulous maxilla: Literature review. Pract J Periodontics Aesthet Dent. 2000; 12:599-608.

38. Romanos, G. E., Javed, F., Delgado-Ruiz, R. A., \& CalvoGuirado, J. L. Peri-implant diseases: a review of treatment interventions. J Dent Clin North Am.2015; 59:157-78. 
39. Sicilia, A., Botticelli, D., \& Working Group 3. Computerguided implant therapy and soft-and hard-tissue aspects. The Third EAO Consensus Conference 2012. J Clin Oral Implant Res.2012; 23:157-161.

40. Greenstein G. Contemporary interpretation of probing depth assessments: Diagnostic and therapeutic indications. J Periodontol. 1996; 68:1194-1205.

41. Panagakos FS, Aboyoussef H, Dondero R, et al. Detection and measure- ment of inflammatory cytokines in implant crevicular fluid: a pilot study. Int J Oral Maxillofac Implants. $1996 ; 11: 794-799$.

42. Stein D, Lee Y, Schmid MJ, et al. Local simvastatin effects on mandibular bone growth and inflammation. J Periodontol. 2005 ; 76:1861-1867.

43. Stoker, G., Van Waas, R. and Wismeijer, D. 'Long-term outcomes of three types of implant-supported mandibular overdentures in smokers'. J Clin Oral Implant Res.2012;23:925-929.

44. Costa, F. O., Takenaka-Martinez, S., Cota, L. O. M., Ferreira, S. D., Silva, G. L. M., \& Costa, J. E. Peri-implant disease in subjects with and without preventive maintenance: a 5-year follow- up. J Clin Periodontol. 2012; 39:173-81.

45. Francetti L, Romeo D, Corbella S, Taschieri S, Del Fabbro $\mathrm{M}$. Bone level changes around axial and tilted implants in full-arch fixed immediate restorations. Interim results of a prospective study. J Clin Implant Dent Relat Res. 2012; 14:646-654.
46. ELsyad, M., Denewar, B. and Elsaih, E. 'Clinical and Radiographic Evaluation of Bar, Telescopic, and Locator Attachments for Implant-Stabilized Overdentures in Patients with Mandibular Atrophied Ridges: A Randomized Controlled Clinical Trial'. Int J Oral Maxillofac Implants.2018; 33: 1103-1111.

47. Kamburo־glu K., Gulsahi A, Genç Y, Paksoy CS. A comparison of peripheral marginal bone loss at dental implants. measured with conventional intraoral $\mathrm{lm}$ and digitized radiographs. J Oral Implantol.2012; 38: 211-19.

48. Kamburoğlu K, Murat S, Kılıç C, Yüksel S, Avsever H, Farman A, Scarfe WC. Accuracy of CBCT images in the assessment of buccal marginal alveolar peri-implant defects: effect of field of view. J DMFR. 2014; 43:20130332.

49. Eitner S, Schlegel A, Emeka N, Holst S, Will J, Hamel J. Comparing bar and double-crown attachments in implantretained prosthetic reconstruction: A follow-up investigation. J Clin Oral Implants Res .2008;19:530 - 537.

50. Elsyad MA, Khirallah AS. Circumferential bone loss around splinted and nonsplinted immediately loaded implants retaining mandibu- lar overdentures: A randomized controlled clinical trial using cone beam computed tomography. J Prosthet Dent .2016;116:741-748.

51. Dellavia C, Canullo L, Allievi C, Lang NP, Pellegrini G. Soft tissue surrounding switched platform implants: an immunohistochemical evaluation. J Clin Oral Impl Res. 2013;24: 63-70. 